\title{
Recombinant human DNase nebulisation in children with cystic fibrosis: before bedtime or after waking up?
}

\author{
L.J. van der Giessen*, R. Gosselink\#, W.C.J. Hop ${ }^{\star}$ and H.A.W.M. Tiddens ${ }^{+}$
}

ABSTRACT: The present study focused on patients with cystic fibrosis (CF), who were on maintenance therapy with recombinant human deoxyribonuclease (rhDNase), with the aim of comparing efficacy and possible side effects of nebulisation of rhDNase when taken before bedtime with efficacy and side effects when taken after waking up.

A randomised, double-blind, double-dummy, crossover study group was used. The inclusion criteria were as follows: 1) CF, 2) stable clinical condition and 3) rhDNase maintenance therapy. Patients in group I inhaled rhDNase before bedtime and a placebo after waking up in weeks 1-2. The protocol was reversed during weeks 3-4. Group II patients performed the reverse of this sequence. Patients continued with their daily routine sputum expectoration. The primary endpoint was classified as the maximal instantaneous forced flow when $25 \%$ of the forced vital capacity remained to be exhaled (MEF25\%). Pulmonary functions tests were performed on days $\mathbf{0}$, 7, 14, 21 and 28. At 1, 2, 3 and 4 weeks arterial oxygen saturation and cough frequency were measured during the night.

A total of 24 patients completed the study. The mean (range) age of the patients was 13 (619) yrs. MEF25\%, taken to be the primary end-point, did not show a significant difference between nebulisation of rhDNase before bedtime compared with when taken after waking up. Nocturnal cough, oxygen saturation, and other secondary end-points were not significantly different between the two study periods.

In conclusion, the present study found that it is equally effective and safe to nebulise recombinant human deoxyribonuclease before bedtime compared with when performed after waking up in children with cystic fibrosis, who are on maintenance treatment with recombinant human deoxyribonuclease.

KEYWORDS: Airway clearance therapy, children, cystic fibrosis, pulmozyme, recombinant human deoxyribonuclease, timing

ystic fibrosis (CF) lung disease is characterised by excess mucus production and impaired mucociliary clearance [1]. This causes the airways to become chronically infected with microorganisms, leading to chronic airway inflammation and progressive structural lung damage [2]. CF sputum contains large amounts of extracellular DNA released by disintegrated inflammatory cells, particularly neutrophils [3, 4]. Patients need daily treatment to reduce the amount of mucus in the airways, though they tend to feel this is a great burden [5]. Airway clearance therapy (ACT) and nebulisation of recombinant human deoxyribonuclease (rhDNase) are the most frequently used methods to mobilise sputum. The rhDNase cleaves extracellular DNA and reduces sputum viscosity, transforming it from a nonflowing viscous gel into a flowing liquid [6]. Daily treatment with rhDNase reduces the number of pulmonary exacerbations, improves pulmonary function, is tolerated well and is safe in mild, moderate and severe CF cases [7-11]. Although the effectiveness of rhDNase nebulisation is well established, little is known regarding optimal timing. The Epidemiologic Registry of Cystic Fibrosis reported that $51 \%$ of patients use rhDNase in the morning, $37 \%$ use it in the evening and $8 \%$ use it at variable times; timing was not specified for $3 \%$ [12].

Theoretically, it could be effective and time efficient for patients to nebulise rhDNase before bedtime. It would allow sufficient time during sleep for rhDNase to act upon the free DNA

\section{AFFILIATIONS}

Depts of *Paediatric Physiotherapy, "Epidemiology and Biostatistics, and, +Paediatric Respiratory Medicine and Allergology, Erasmus MC, Sophia Children's Hospital, Rotterdam, the Netherlands.

\#Dept of Respiratory Rehabilitation, University Hospitals, KU Leuven, Belgium.

CORRESPONDENCE

L.J. van der Giessen Dr Molewaterplein 60 3015 GJ Rotterdam The Netherlands

Fax: 31104636811

E-mail: I.vandergiessen@

erasmusmc.nl

Received:

March 152007

Accepted after revision:

June 112007

STATEMENT OF INTEREST

Statements of interest for L.J. van der Giessen and H.A.W.M. Tiddens, the study itself and the Erasmus MC, Sophia Children's Hospital, can be found at www.erj.ersjournals.com/ misc/statements.shtml

European Respiratory Journa Print ISSN 0903-1936 Online ISSN 1399-3003 
present in the airway lumen. Its half-life in rodents was found to be $\geqslant 11 \mathrm{~h}$ after inhalation [13]. Secondly, postural shifts during sleep might act like postural drainage therapy; allowing gravity-dependent mobilisation of the sputum. Adults were found to have an average of 16 position shifts per night [14]. Postural drainage is reported to be effective when relatively large quantities of mucus of low adhesion are present in the airways [15]. Following nebulisation of rhDNase the mucus will become less viscous. Postural drainage during sleep is therefore likely to improve mucociliary clearance.

Alternatively, there are several theoretical arguments against the nebulisation of rhDNase before bedtime. There are indications that mucociliairy clearance is depressed during sleep in normal subjects [16] and in subjects with asthma [17]. However, in CF patients, the dehydrated secretions are capable of triggering coughing spells during sleep [18]. Secondly, nightly spontaneous cough might be less effective to expectorate the sputum relative to daytime cough or active ACT. Hence, bedtime nebulisation of rhDNase might be detrimental to lung function. Thirdly, nebulisation-induced cough increased during sleep might affect sleep quality [18]. Finally, nebulisation of rhDNase before bedtime might induce ventilation/perfusion mismatch due to additional occlusion of peripheral airways by the more liquid mucus. However, this has never been systematically studied.

The current authors conducted a study in children with CF on maintenance therapy with rhDNase, comparing the efficacy and possible side effects of nebulisation before bedtime with those of nebulisation after waking up. Efficacy was evaluated using pulmonary function tests. Side effects were monitored using nocturnal oxygen saturation and cough frequency. The present authors hypothesised that nebulisation of rhDNase before bedtime would be safe and more effective in improving peripheral airway flow when compared with nebulisation after waking up.

\section{MATERIAL AND METHODS \\ Study subjects}

Children attending the CF centre in the Erasmus MC, Sophia Children's Hospital (Rotterdam, the Netherlands) were considered eligible for inclusion in the present study when they fulfilled the following criteria: 1) proven $\mathrm{CF}$; 2) minimum age of $5 \mathrm{yrs}$; 3) the ability to perform reproducible spirometry, forced vital capacity (FVC) $>40 \%$; 4) daily ACT, 5) maintenance treatment with rhDNase; and 6) clinical stability. The latter was defined as no need for intravenous antibiotics and no hospitalisations for a minimum of 1 month prior to the study. CF was defined as clinical symptoms characteristic for CF plus an abnormal sweat test and/or the presence of two CF mutations. The current authors excluded children who used rhDNase more than once a day and were considered to have poor therapy compliance $(<50 \%$ of treatments) as judged by the CF team; or those with learning difficulties.

A total of $152 \mathrm{CF}$ patients were identified. Of these, 49 patients did not meet the study inclusion criteria. Most patients were excluded on the basis that they were too young to perform spirometry. From the remaining 103 patients, 43 were randomly selected and invited to participate. Throughout the study, subjects continued to receive their standard treatment.

\section{Study design}

The study had a randomised, double-blind, double-dummy, crossover design. All subjects nebulised both rhDNase $(2.5 \mathrm{mg}$ of rhDNase in $2.5 \mathrm{~mL}$ buffered solution: $8.77 \mathrm{mg} \cdot \mathrm{mL}^{-1} \mathrm{NaCl}$ and $\left.0.15 \mathrm{mg} \cdot \mathrm{mL}^{-1} \mathrm{CaCl}\right)$ [19] and a placebo $(2.5 \mathrm{~mL}$ of a buffered solution: $8.77 \mathrm{mg} \cdot \mathrm{mL}^{-1} \mathrm{NaCl}$ and $0.15 \mathrm{mg} \cdot \mathrm{mL}^{-1} \mathrm{CaCl}$ ) for a period of 4 weeks. Placebo was similar to rhDNase in both colour and taste. Subjects were randomised into one of two groups. Group I used rhDNase before bedtime and placebo in the morning directly after waking up in the first 2 weeks. This order was reversed in the following two weeks (fig. 1). Group II used placebo before bedtime and rhDNase after waking up in the 2 weeks and in the reverse sequence thereafter.

Based on previous studies, weeks 1 and 3 were considered wash-in and wash-out periods [10, 20, 21]. As patients were on maintenance treatment with rhDNase, a true wash-out period without rhDNase was considered unethical and unpractical. Patients continued to perform routine ACT during the study period. ACT in the morning was performed $30 \mathrm{~min}$ after nebulisation.

Placebo and rhDNase were administered using a Sidestream nebuliser (Respironics, Murrysville, PA, USA) and one of the following compressors: Portaneb, Freeway Lite, Freeway Freedom or CR60 (all Respironics).

The present authors selected the maximal instantaneous forced flow when $25 \%$ of the FVC remained to be exhaled (MEF25\%) as the primary end-point, as it is more sensitive to changes in the peripheral compartment in early lung disease compared with FVC and forced expiratory volume in one second (FEV1) [22].

The study was conducted between September 2005 and June 2006. The Erasmus MC Medical Ethical Review Board approved the protocol. The study was performed according to the International Conference on Harmonisation and World Health Organization Good Clinical Practice standards guidelines [23].

\section{Equipment specifications}

Pulmonary function tests (PFTs) were carried out using a handheld spirometer (MicroLoop; Micro Medical Ltd,

\begin{tabular}{|c|c|c|c|}
\hline \multicolumn{2}{|c|}{$\begin{array}{c}\text { rhDNase at night-time } \\
\text { Placebo in the morning }\end{array}$} & \multicolumn{2}{|c|}{$\begin{array}{c}\text { rhDNase in the morning } \\
\text { Placebo at night-time }\end{array}$} \\
\hline 7 days & 7 days & 7 days & 7 days \\
\hline & Diary & & Diary \\
\hline Baseline PFT & \multicolumn{3}{|c|}{$\begin{array}{c}\text { PFT } \\
\text { Cough measurement } \\
\text { Nocturnal saturation }\end{array}$} \\
\hline
\end{tabular}

FIGURE 1. Study design and time points for the primary and secondary endpoint measurements for children in group I. In group II the order of the recombinant human deoxyribonuclease (rhDNase) and the placebo were reversed. PFT: pulmonary function test. 


\section{TABLE 1 Cough symptom scoring}

\begin{tabular}{lcc} 
Score & Daytime & Night-time \\
\hline $\mathbf{0}$ & No cough & No cough \\
$\mathbf{1}$ & Cough for one or two short periods & Cough on waking only/cough on going to sleep only \\
$\mathbf{2}$ & Cough for more than two short periods & Awoken once or woken early due to coughing \\
$\mathbf{3}$ & Frequent cough not interfering with normal activities & Frequent waking due to coughing \\
$\mathbf{4}$ & Frequent cough interfering with school or other activities & Frequent coughs most of the night \\
$\mathbf{5}$ & Distressing cough most of the day & Distressing cough
\end{tabular}

Rochester, UK). The following PFT results were obtained: FEV1, FVC and MEF25\%. The PFT results were expressed as a percentage of predicted values [24]. Interrupter resistance (Rint, $\mathrm{kPa} \cdot \mathrm{L}^{-1} \cdot \mathrm{s}^{-1}$ ) was measured using the MicroRint (Micro Medical Ltd). Calibrations of flow were carried out using a $1-\mathrm{L}$ precision pump.

\section{Procedures}

PFTs were carried out at the patient's home. Weight and height were measured on day 0 . Rint measurements and spirometry were performed on days $0,7,14,21$ and 28, Rint was always measured first. Throughout the study, the lung function measurements were performed using the same spirometer in the afternoon and on the same day of the week for each patient. Before PFTs were performed the children were asked to clear their throat by coughing. For Rint measurements the children were instructed to sit upright while breathing quietly. The head was positioned in slight extension. The hands of the investigator supported the patient's cheeks and chin to reduce upper airway compliance [25]. A test measurement was done before the actual measurements to familiarise children with the sound of the shutter. A minimum of five correct tracings (maximal 10) were obtained. The expiratory Rint (Rint,e) was measured, because expiratory interruptions are more sensitive in detecting airway obstruction relative to inspiratory interruptions [26]. Spirometry was performed in triplicate according to European Respiratory Society guidelines [27].

For those patients who used tobramycin solution for inhalation (TSI) the study took place during the 4-week TSI-free interval. To estimate adherence to the study medication, patients were asked to keep empty drug vials for vial count.

Arterial oxygen saturation was determined by pulse oximetry (Mars Pulse oximeter; Respironics) during nights 7, 14, 21, and 28. To measure the nocturnal oxygen saturation profile, a pulse oximeter sensor was attached to either the subject's finger or toe during sleep. Data were stored on the pulse oxymeter. From this recording, the mean oxygen saturation was calculated.

Cough recordings were made on a digital audio player/ recorder (Archos ${ }^{\mathrm{TM}}$ Gmini 120; Archos, Shenzhen, China) during nights 7, 14, 21 and 28, and then transferred to a computer. The recordings were analysed using free Open Source audio record and edit software, which provided a graphical display for audio analysis applications (Audacity, Boston, USA).

A cough episode was identified by having at least one explosive cough present. The duration of each cough episode was counted in seconds (cough seconds (cs)). If several cough sounds occurred successively the duration of the total episode was counted. Cough per hour $\left(\mathrm{cs} \cdot \mathrm{h}^{-1}\right)$ was then calculated by summing the total cs and dividing by the total recording time. This measure therefore encompasses an estimate of the length of peals of coughs [28]. Counting of cough sounds from digital audio recordings has excellent agreement with simultaneous video recordings [29].

During weeks 2 and 4 the children recorded in a diary their day and night-time cough frequencies with a validated cough symptom score (CSS; table 1) [30]. They also rated sputum viscosity, sputum production, sleep quality, appetite in the morning and cough frequency on a visual analogue scale (VAS) [30]. A VAS is a horizontal line, $10 \mathrm{~cm}$ in length, anchored by word descriptors at each end. Rating is done by placing a mark on this line in the position that best represents the child's perception. The VAS score is the distance in $\mathrm{cm}$ between no symptom (left $=0 \mathrm{~cm}$ ) and the mark placed by the patient.

\section{Data analysis}

The pre-planned primary outcome variable was MEF25\%. With 24 evaluated patients, the power for this parameter in the comparison of the two treatment schedules would be $>80 \%$ for an effect-size (difference of mean \pm SD) of 0.8 at an alpha (twosided) of 5\%. Secondary outcome variables were FVC \% pred, FEV1 \% pred, Rint,e, oxygen saturation, cough frequency and diary scores.

Outcome variables were compared using the paired t-test after ensuring that there was no significant carry-over or period effects. The mean values of diary scores for weeks 2 and 4 were analysed. Statistical analyses were performed and $p=0.05$ (two-sided) was considered the limit of significance in all analyses.

\section{RESULTS}

From the 43 randomly selected children, 13 children declined to participate and five did not respond. The study group included 25 children, randomly divided between group I (12) and group II (13). Final analysis was for 24 children, as one child, randomised to group I, withdrew in week 3 due to a common flu. Baseline characteristics are summarised in table 2; type of ACT and nebulisers are listed in table 3. The two randomised groups were comparable at baseline with respect to age, sex and lung function (table 2). No carry-over or period effect was observed for any of the end-points. Mean adherence to the study treatment, as calculated from the vial count, was $97 \%$ (range $82-100 \%$ ). 


\begin{tabular}{|c|c|c|}
\hline \multirow[t]{2}{*}{ TABLE 2} & \multicolumn{2}{|c|}{$\begin{array}{l}\text { Characteristics of the study population at } \\
\text { baseline for group I and II }\end{array}$} \\
\hline & Group I & Group II \\
\hline Patients & 11 & 13 \\
\hline \multicolumn{3}{|l|}{ Sex } \\
\hline Male & 3 & 5 \\
\hline Female & 8 & 8 \\
\hline Age yrs & $12.5 \pm 4.5$ & $13.5 \pm 3.4$ \\
\hline FVC \% pred & $81 \pm 9$ & $82 \pm 22$ \\
\hline FEV $1 \%$ pred & $74 \pm 12$ & $76 \pm 27$ \\
\hline MEF25\% \% pred & $49 \pm 32$ & $49 \pm 34$ \\
\hline Rint,e $\mathrm{kPa} \cdot \mathrm{L}^{-1} \cdot \mathrm{s}^{-1}$ & $0.5 \pm 0.21$ & $0.5 \pm 0.23$ \\
\hline Use of TSI & 3 & 5 \\
\hline
\end{tabular}

Data are presented as $\mathrm{n}$ or mean $\pm \mathrm{SD}$. In the first 2 weeks, group I nebulised recombinant human deoxyribonuclease (rhDNase) before bedtime and placebo in the morning, directly after waking up. In the following 2 weeks the order in which rhDNase and placebo were taken was reversed. Group II nebulised placebo before bedtime and rhDNase after waking up in the first 2 weeks and performed the reverse sequence thereafter. FVC: forced vital capacity; \% pred: $\%$ predicted; FEV1: forced vital capacity in one second; MEF25\%: maximal instantaneous forced flow when $25 \%$ of the FVC remained to be exhaled; Rint,e: interrupter resistance exhaled; TSI: tobramycin solution for inhalation.

The primary end-point, MEF25\%, did not significantly differ $(\mathrm{p}=0.25)$ between after waking up (a) or before bedtime nebulisation (b): the difference (a minus b) after 2 weeks was 3.38 (95\% confidence interval (CI): -2.6-9.3\%; fig 2).

None of the secondary end-points or safety parameters significantly differed between the two schedules (tables 4 and 5).

\section{DISCUSSION}

In the current study the authors tested the hypothesis that before-bedtime nebulisation of rhDNase would be safe and prove more effective than nebulisation after waking up. However, the current findings do not support the last part of the hypothesis. Both the primary end-point MEF25\% and

\begin{tabular}{|c|c|c|}
\hline TABLE 3 & \multicolumn{2}{|c|}{$\begin{array}{l}\text { Maintenance treatment undertaken by patients } \\
\text { during the study }\end{array}$} \\
\hline \multicolumn{3}{|l|}{ ACT } \\
\hline \multicolumn{2}{|l|}{ PEP mask } & $15(62)$ \\
\hline \multicolumn{2}{|l|}{ Flutter } & $3(13)$ \\
\hline \multicolumn{2}{|c|}{ Autogenic drainage } & $4(17)$ \\
\hline \multicolumn{2}{|c|}{ Combination } & $2(8)$ \\
\hline \multicolumn{3}{|l|}{ Nebuliser } \\
\hline \multicolumn{2}{|l|}{ Portaneb } & $12(50)$ \\
\hline \multicolumn{2}{|c|}{ Freeway Lite } & $1(4)$ \\
\hline \multicolumn{2}{|c|}{ Freeway Freedom } & $9(38)$ \\
\hline \multicolumn{2}{|c|}{ Freeway Elite } & $1(4)$ \\
\hline \multicolumn{2}{|l|}{ CR60 } & $1(4)$ \\
\hline
\end{tabular}

Data are presented as $n(\%)$. PEP: positive expiratory pressure. Manufacturer of all nebulisers presented in table: Respironics, Murrysville, PA, USA.

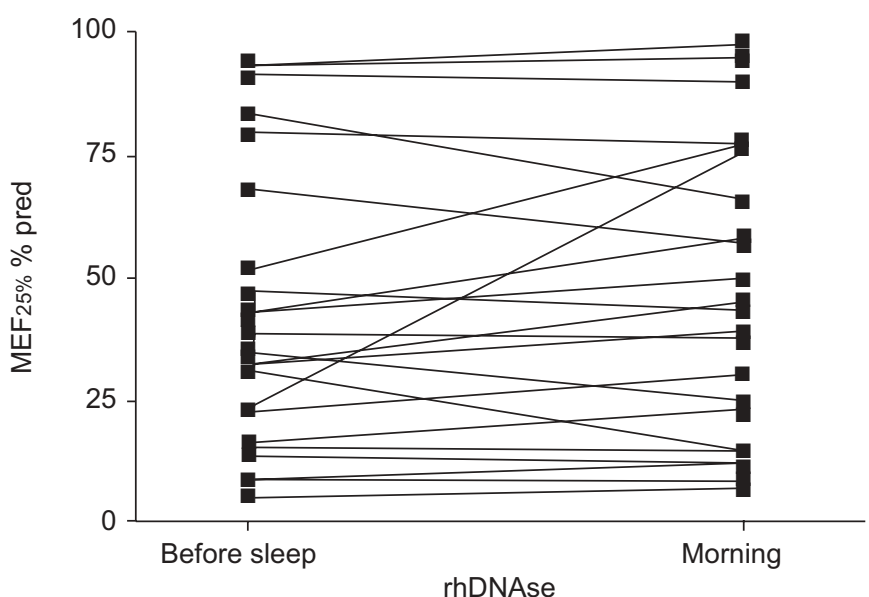

FIGURE 2. Shows the maximal instantaneous forced flow when $25 \%$ of the forced vital capacity remained to be exhaled (MEF25\%) as \% predicted, according to nebulisation of rhDNase at night-time and in the morning, after 2 weeks. rhDNase: recombinant human deoxyribonuclease.

secondary end-points, such as cough frequency and nocturnal oxygen saturation, did not show significant improvement after 2 weeks of nebulising rhDNase before bedtime, compared with nebulisation after waking up. In addition, cough frequency and nocturnal oxygen saturation were not significantly different between the study periods; this supports the first part of the hypothesis, i.e. that nebulisation of rhDNase before bedtime would be safe.

TABLE 4 Results from patients using recombinant human deoxyribonuclease (rhDNase) before bedtime or in the morning after week 1 and 2

rhDNase
Bedtime $\quad$ Morning

\begin{tabular}{lccc} 
After 1 week & & & \\
MEF25\% \% pred & $47.2 \pm 30.0$ & $45.5 \pm 29.9$ & 0.59 \\
FVC \% pred & $83.3 \pm 18.8$ & $83.0 \pm 16.8$ & 0.78 \\
FEV 1 \% pred & $75.5 \pm 21.4$ & $75.1 \pm 21.6$ & 0.82 \\
Rint, & $0.51 \pm 0.22$ & $0.55 \pm 0.27$ & 0.18 \\
Oxygen saturation \% & $95.5 \pm 1.3$ & $95.8 \pm 1.9$ & 0.61 \\
Cough $\left(\mathrm{cs}^{-1} \mathrm{~h}^{-1}\right.$ ) & $2.7 \pm 4$ & $3.7 \pm 4$ & 0.24 \\
After 2 weeks & & & \\
MEF25\% \% pred & $43.0 \pm 28.4$ & $46.4 \pm 28.5$ & 0.25 \\
FVC \% pred & $83.0 \pm 18.8$ & $83.1 \pm 17.7$ & 0.97 \\
FEV $1 \%$ pred & $74.2 \pm 21.8$ & $75.5 \pm 20.6$ & 0.38 \\
Rint,e & $0.54 \pm 0.27$ & $0.54 \pm 0.23$ & 0.97 \\
Oxygen saturation \% & $96.1 \pm 1.6$ & $96.2 \pm 1.4$ & 0.78 \\
Cough $\left(\mathrm{cs} \cdot \mathrm{h}^{-1}\right.$ ) & $3.3 \pm 5$ & $3.7 \pm 8$ & 0.85 \\
\hline
\end{tabular}

Data are presented as mean \pm SD unless otherwise stated. MEF $25 \%$ : maximal instantaneous forced flow when $25 \%$ of the forced vital capacity (FVC) remained to be exhaled; \% pred: \% predicted; FEV1: forced expiratory volume in one second; Rint,e: interrupter resistance exhaled; cs: cough seconds. 


\begin{tabular}{|c|c|c|c|c|}
\hline \multirow[t]{3}{*}{ TABLE 5} & \multicolumn{4}{|c|}{$\begin{array}{l}\text { Diary scores after } 2 \text { weeks use of recombinant } \\
\text { human deoxyribonulease (rhDNase) taken } \\
\text { before bedtime or after waking up }\end{array}$} \\
\hline & & \multicolumn{2}{|c|}{ rhDNase } & \multirow[t]{2}{*}{ p-value } \\
\hline & & Bedtime & Morning & \\
\hline \multicolumn{5}{|l|}{ VAS } \\
\hline Viscosity & & $2.1 \pm 1.6$ & $2.5 \pm 1.6$ & 0.22 \\
\hline Sputum am & unt & $1.9 \pm 1.8$ & $2.1 \pm 1.6$ & 0.26 \\
\hline Daytime co & ghing & $2.2 \pm 1.6$ & $2.5 \pm 1.7$ & 0.27 \\
\hline Night-time & oughing & $1.0 \pm 1.0$ & $1.3 \pm 1.4$ & 0.08 \\
\hline Appetite & & $3.0 \pm 2.7$ & $3.3 \pm 2.6$ & 0.35 \\
\hline Sleep qualit & & $1.1 \pm 1.0$ & $1.5 \pm 1.3$ & 0.08 \\
\hline \multicolumn{5}{|l|}{ css } \\
\hline Daytime & & $1.3 \pm 0.9$ & $1.6 \pm 0.9$ & 0.07 \\
\hline Night-time & & $0.8 \pm 0.8$ & $1.0 \pm 0.9$ & 0.27 \\
\hline
\end{tabular}

The present authors feel that several possible explanations present themselves as to why no improved efficacy after nebulisation before bedtime was found. First, sputum after nebulisation with rhDNase might still be too viscous to allow any extra positive effect by gravity. Secondly, during sleep mucociliary clearance is depressed $[16,17]$ and breathing patterns change, resulting in reduced minute ventilation and tidal breathing pattern [31, 32] as well as an increased airway resistance [33]. If gravity and mucociliary clearance fail to mobilise the viscous sputum spontaneously, it can only be cleared by high expiratory flows [34]. However, sleep is mostly characterised by quiet tidal volume breathing, which is likely to contribute little or nothing to sputum transport. Thirdly, the 2-week treatment period in each arm may have been too short. In a recent study by VAN DER GIESSEN et al. [35], who compared the effect of nebulisation of rhDNase before and after ACT, the primary end-point MEF $25 \%$ showed no significant difference after 2 weeks, but after 3 weeks a significant increase by $6 \%$ was observed when rhDNase was used $30 \mathrm{~min}$ before ACT. A longer study period might have resulted in a difference between the two treatment arms. The result of the previous study was not known when the current study started. Extension of the treatment period implied exclusion of those patients treated with TSI, since TSI greatly influences spirometry results [36]. Alternatively, each treatment arm could have been scheduled into the TSI negative or positive treatment period. However, this approach would have made the total study duration for each patient longer with the risk of higher noise and drop-out rates. The absence of differences in nocturnal cough frequency or oxygen saturation between treatment arms suggests no major differences in sputum mobilisation.

A positive finding was that before-bedtime rhDNase administration did not result in increased cough or reduced oxygen saturation during the night in this group of patients with mildto-moderate lung function abnormalities. As suggested by some physicians, before-bedtime rhDNase could have increased nightly cough periods due to its effect on the sputum. The current authors did not find any increase in $\mathrm{cs} \cdot \mathrm{h}^{-1}$ when rhDNase was nebulised before bedtime. This might have been the result of the depressed cough reflex during sleep [37]. Such a condition could prevent the liquefied sputum from being evacuated by cough clearance. However, the present authors believe this is unlikely, since oxygen saturation did not differ between the two study periods. Substantial increase of peripheral airway obstruction due to liquefied sputum would have resulted in more severe ventilation/perfusion mismatch and thus, in reduced oxygen saturation. The oxygen saturation finding is therefore in line with the present PFT and cough results.

In contrast to the present authors' expectations, the children showed a trend towards better sleep quality and less daytime and night-time cough (table 5) when rhDNase was nebulised before bedtime. Nebulisation of rhDNase before bedtime in patients with mild-to-moderate lung function abnormalities seems therefore to be safe.

How do the current study's results translate to daily treatment for CF patients? Based on the present findings, there are no arguments against the pre-sleep rhDNase treatment. However, long-term studies in larger cohorts and with additional secondary end-points, such as exacerbation rate, are needed to confirm the current study's results.

The present authors cannot argue that their observations would have been different for children with severe or endstage lung disease. This must be investigated in a separate controlled trial, using similar monitoring of safety end-points.

In conclusion, this study showed that for children with cystic fibrosis on maintenance treatment with recombinant human deoxyribonuclease, it is equally effective and safe to nebulise recombinant human deoxyribonuclease before bedtime and to perform airway clearance therapy in the morning as it is to nebulise recombinant human deoxyribonuclease after waking up by airway clearance therapy. It is therefore up to the children themselves to choose the most convenient time to nebulise recombinant human deoxyribonuclease.

\section{ACKNOWLEDGEMENTS}

The authors would like to thank: the patients and their parents for participating in this study; and K. Hagoort and B. E. Schuurman (Sophia Children's Hospital, Erasmus MC, Rotterdam, the Netherlands) for critical reading of the manuscript.

\section{REFERENCES}

1 FitzSimmons SC. The changing epidemiology of cystic fibrosis. J Pediatr 1993; 122: 1-9.

2 de Jong PA, Nakano Y, Lequin MH, et al. Progressive damage on high resolution computed tomography despite stable lung function in cystic fibrosis. Eur Respir J 2004; 23: 93-97.

3 Costello CM, O'Connor CM, Finlay GA, Shiels P, FitzGerald MX, Hayes JP. Effect of nebulised recombinant DNase on neutrophil elastase load in cystic fibrosis. Thorax 1996; 51: 619-623.

4 Henke MO, Renner A, Huber RM, Seeds MC, Rubin BK. MUC5AC and MUC5B mucins are decreased in cystic 
fibrosis airway secretions. Am J Respir Cell Mol Biol 2004; 31: 86-91.

5 Morgan WJ, Butler SM, Johnson CA, et al. Epidemiologic study of cystic fibrosis: design and implementation of a prospective, multicenter, observational study of patients with cystic fibrosis in the US and Canada. Pediatr Pulmonol 1999; 28: 231-241.

6 Shak S, Capon DJ, Hellmiss R, Marsters SA, Baker CL. Recombinant human DNase I reduces the viscosity of cystic fibrosis sputum. Proc Natl Acad Sci USA 1990; 87: 9188-9192.

7 Kearney CE, Wallis CE. Deoxyribonuclease for cystic fibrosis. Cochrane Database Syst Rev 2000; 2: CD001127.

8 Fuchs HJ, Borowitz DS, Christiansen DH, et al. Effect of aerosolized recombinant human DNase on exacerbations of respiratory symptoms and on pulmonary function in patients with cystic fibrosis. The Pulmozyme Study Group. N Engl J Med 1994; 331: 637-642.

9 Quan JM, Tiddens HA, Sy JP, et al. A two-year randomized, placebo-controlled trial of dornase alfa in young patients with cystic fibrosis with mild lung function abnormalities. J Pediatr 2001; 139: 813-820.

10 Ramsey BW, Astley SJ, Aitken ML, et al. Efficacy and safety of short-term administration of aerosolized recombinant human deoxyribonuclease in patients with cystic fibrosis. Am Rev Respir Dis 1993; 148: 145-151.

11 Hodson ME, McKenzie S, Harms HK, et al. Dornase alfa in the treatment of cystic fibrosis in Europe: a report from the Epidemiologic Registry of Cystic Fibrosis. Pediatr Pulmonol 2003; 36: 427-432.

12 ERCF. ERCF Annual Report 1998: F. Hoffmann-La Roche Ltd; 2000.

13 Green JD. Pharmaco-toxicological expert report Pulmozyme rhDNase Genentech, Inc. Hum Exp Toxicol 1994; 13: Suppl. 1, S1-42.

14 Lorrain D, De Koninck J, Dionne H, Goupil G. Sleep Positions and postural shifts in elderly persons. Percept Mot Skills 1986; 63: 352-354.

15 Houtmeyers E, Gosselink R, Gayan-Ramirez G, Decramer M. Regulation of mucociliary clearance in health and disease. Eur Respir J 1999; 13: 1177-1188.

16 Bateman JRM, Pavia D, Clarke SW. The retention of lung secretions during the night in normal subjects. Clin Sci Mol Med 1978; 55: 523-527.

17 Hasani A, Agnew JE, Pavia D, Vora H, Clarke SW. Effect of oral bronchodilators on lung mucociliary clearance during sleep in patients with asthma. Thorax 1993; 48: 287-289.

18 Stokes DC, McBride JT, Wall MA, Erba G, Strieder DJ. Sleep hypoxemia in young adults with cystic fibrosis. Am J Dis Child 1980; 134: 741-743.

19 Pulmozyme. Product monograph update 2. GardinerCaldwell Communications, 2002; pp. 3-65.

20 Shah PL, Scott SF, Geddes DM, Hodson ME. Two years experience with recombinant human DNase I in the treatment of pulmonary disease in cystic fibrosis. Respir Med 1995; 89: 499-502.

21 Shah PI, Bush A, Canny GJ, et al. Recombinant human DNase I in cystic fibrosis patients with severe pulmonary disease: a short-term, double-blind study followed by six months open-label treatment. Eur Respir J 1995; 8: 954-958.

22 Tiddens HA. Detecting early structural lung damage in cystic fibrosis. Pediatr Pulmonol 2002; 34: 228-231.

23 ICH (1996). International Conference on Harmonisation (ICH) Tripartite Guideline. ICH, Gereva, 1996.

24 Zapletal A, Samanek M, Paul T. Lung Function in Children and Adolescents (Progress in Respiratory Research). Basel, Karger; 1987.

25 Hadjikoumi I, Hassan A, Milner AD. Effects of respiratory timing and cheek support on resistance measurements, before and after bronchodilation in asthmatic children using the interrupter technique. Pediatr Pulmonol 2003; 36: 495-501.

26 Merkus PJ, Mijnsbergen JY, Hop WC, de Jongste JC. Interrupter resistance in preschool children: measurement characteristics and reference values. Am J Respir Crit Care Med 2001; 163: 1350-1355.

27 Miller MR, Hankinson J, Brusasco V, et al. Standardisation of spirometry. Eur Respir J 2005; 26: 319-338.

28 Smith J, Owen E, Earis J, Woodcock A. Cough in COPD: correlation of objective monitoring with cough challenge and subjective assessments. Chest 2006; 130: 379-385.

29 Smith JA, Earis JE, Woodcock A. Establishing a gold standard for manual cough counting: video versus digital audio recordings. Cough 2006; 2: 6.

30 Chang AB, Newman RG, Carlin JB, Phelan PD, Robertson CF. Subjective scoring of cough in children: parent-completed vs child-completed diary cards $v s$ an objective method. Eur Respir J 1998; 11: 462-466.

31 Tepper RS, Skatrud JB, Dempsey JA. Ventilation and oxygenation changes during sleep in cystic fibrosis. Chest 1983; 84: 388-393.

32 George CF, West P, Kryger MH. Oxygenation and breathing pattern during phasic and tonic REM in patients with chronic obstructive pulmonary disease. Sleep 1987; 10: 234-243.

33 Henke KG, Badr MS, Skatrud JB, Dempsey JA. Load compensation and respiratory muscle function during sleep. J Appl Physiol 1992; 72: 1221-1234.

34 van der Schans C. Physiotherapy and Bronchial Mucus Transport. Groningen, Rijksuniversiteit, 1991.

35 van der Giessen LJ, de Jongste JC, Gosselink R, Hop WC, Tiddens HA. RhDNase before airway clearance therapy improves airway patency in children with CF. Pediatr Pulmonol 2007; 42: 624-630.

36 Ramsey BW, Pepe MS, Quan JM, et al. Intermittent administration of inhaled tobramycin in patients with cystic fibrosis. Cystic Fibrosis Inhaled Tobramycin Study Group. N Engl J Med 1999; 340: 23-30.

37 Widdicombe J, Fontana G. Cough: what's in a name? Eur Respir J 2006; 28: 10-15. 